Table 1.

\begin{tabular}{|c|c|c|}
\hline & $\begin{array}{c}\text { Audit } \\
(n=25)\end{array}$ & $\begin{array}{c}\text { Re-audit } \\
(n=29)\end{array}$ \\
\hline \multicolumn{3}{|c|}{ Compliance } \\
\hline Q1. Documented evidence of joint count being performed? & $84.0 \%$ & $100.0 \%$ \\
\hline $\begin{array}{l}\text { Q2. If yes, then was it a } 66 / 68 \text { count for swollen and tender } \\
\text { joints? }\end{array}$ & $4.7 \%$ & $100.0 \%$ \\
\hline Q3. Documented evidence of dactylitis being assessed? & $8.0 \%$ & $100.0 \%$ \\
\hline Q4. Documented evidence of enthesitis being assessed? & $4.0 \%$ & $100 \%$ \\
\hline $\begin{array}{l}\text { Q5. Documented evidence of assessment of spinal } \\
\text { involvement? }\end{array}$ & $8.0 \%$ & $100.0 \%$ \\
\hline $\begin{array}{l}\text { Q6. Documented evidence of assessment of skin } \\
\text { involvement? }\end{array}$ & $36.0 \%$ & $100.0 \%$ \\
\hline Q7. Documented evidence of assessment of nail involvement? & $4.0 \%$ & $93.1 \%$ \\
\hline Q8. Documented evidence of assessment of fatigue? & $8.0 \%$ & $96.6 \%$ \\
\hline Q9. Documented evidence of assessment of degree of pain? & $60.0 \%$ & $100.0 \%$ \\
\hline Q10. Documented evidence of patient's global assessment? & $68.0 \%$ & $96.6 \%$ \\
\hline $\begin{array}{l}\text { Q11. Documented evidence of assessment of physical } \\
\text { function? }\end{array}$ & $0.0 \%$ & $96.6 \%$ \\
\hline $\begin{array}{l}\text { Q12. Documented evidence of assessment of health-related } \\
\text { quality of life? }\end{array}$ & $0.0 \%$ & $93.1 \%$ \\
\hline $\begin{array}{l}\text { Q13. Documented evidence of assessment of systemic } \\
\text { inflammation? }\end{array}$ & $72.0 \%$ & $96.6 \%$ \\
\hline Overall Compliance & $27.4 \%$ & $97.9 \%$ \\
\hline
\end{tabular}

Conclusion: Dedicated PsA clinics using the GRAPPA App on iPads could facilitate comprehensive multi-domain assessments of patients with PsA and potentially lead to better outcomes as well as greater patient satisfaction.

References:

[1] Orbai AM et al., (2017) Updating the psoriatic arthritis (PsA) core domain set: a report from the PsA workshop at OMERACT 2016. J Rheumatol 44(10):1522-1528

[2] Coates LC et al., Effect of tight control of inflammation in early psoriatic arthritis (TICOPA): a UK multicentre, open-label, randomised controlled trial. Lancet. 2015; 386(10012):2489-2498

Figure 1. Patient survey $(n=26)$

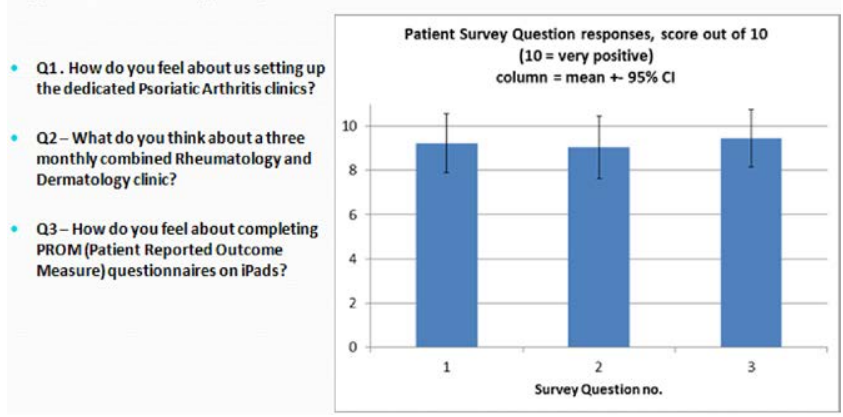

Acknowledgments

Disclosure of Interests: None declared

DOI: 10.1136/annrheumdis-2020-eular.1111

\section{AB0809 HOW WELL ARE BIOLOGICS RETAINED IN PSORIATIC ARTHRITIS - A REAL WORLD STUDY}

I. Jawad ${ }^{1}$, M. K. Nisar2. ${ }^{1}$ Luton and Dunstable University Hospital, Rheumatology, Luton, United Kingdom; ' ${ }^{1}$ Luton and Dunstable University Hospital, Rheumatology, Luton, United Kingdom

Background: Biologics have led to a sea change in the management of psoriatic arthritis (PsA) with unprecedented improvement in the signs, symptoms and radiographic damage, resulting in improvement in functionality and quality of life. However longitudinal data for their retention and tolerability is sparse.

Objectives: Our objective was to evaluate real-world biologic therapy duration and reasons for discontinuing treatment.

Methods: We conducted a retrospective analysis of our PsA electronic register from 1994 up to and including April 2019 at our university teaching hospital. We had access to full patient records including details on co-morbidities, drugs and disease management.

Results: 335 patients were identified with PsA. $58 \%$ of them were female with mean age of $46 \mathrm{yr}$ (13-81). 113 (33.7\%) patients had been treated with a biologic with 105 (93\%) continuing at the time of analysis. 60 individuals were prescribed combination therapy with DMARDs. Mean age was 43.3 years (13-81) with $56 \%$ women. The biologics sample was ethnically diverse including $80 \%$ White Caucasian patients, $17 \%$ Asian and others (3\%). Significant co-morbidities included cardiovascular disease (18.6\%) and diabetes (4.4\%). Eight different biologics were in use with adalimumab being the most prescribed $(67 \%)$.

$35(30.9 \%)$ patients had stopped biologics at some point with 76 episodes of cessation. $6 \%$ of our sample had discontinued two or more biologic treatments. The mean duration before biologic therapy was discontinued was 18.2 months ( 8 days to 9.5 years), which was almost twice as long as the average period before discontinuing a DMARD (9.9 months). Main reasons for stopping treatment included $23 \%$ each due to Gl symptoms, neurological causes, cutaneous symptoms and other side effects. The remaining $8 \%$ reported fatigue as the reason for stopping therapy.

Conclusion: To our knowledge this is the first dedicated retrospective review of a large real world PsA cohort comparing drug survival and tolerability of biologics against DMARDs. Biologic therapies are well tolerated in psoriatic arthritis. There is no significant difference amongst various modes of action. Over a quarter of the patients discontinue the drug owing to intolerance with mean drug survival of 18 months. In contrast nearly two-thirds were intolerant of DMARDs and stopped within ten months. Thus both the rate and duration of biologic retention is significantly better than conventional DMARDs. This has significant economic impact as NICE guidelines require an adequate trial of two DMARDs for six months prior to advanced therapy. However, this approach is unlikely to be cost effective as the disease progresses whilst patients struggle with DMARDs prescription and thus delay biologics which are more likely to be tolerated and retained longer. Hence there is an urgent need to review NICE guidelines to allow earlier employment of biologics in the treatment paradigm with significant benefits to both patients and the health economy.

Disclosure of Interests: Issrah Jawad: None declared, Muhammad Khurram Nisar Grant/research support from: Muhammad Nisar undertakes clinical trials and received support (including attendance at conferences, speaker fees and honoraria) from Roche, Chugai, MSD, Abbvie, Pfizer, BMS, Celgene, Novartis and UCB, Consultant of: Muhammad Nisar undertakes clinical trials and received support (including attendance at conferences, speaker fees and honoraria) from Roche, Chugai, MSD, Abbvie, Pfizer, BMS, Celgene, Novartis and UCB, Speakers bureau: Muhammad Nisar undertakes clinical trials and received support (including attendance at conferences, speaker fees and honoraria) from Roche, Chugai, MSD, Abbvie, Pfizer, BMS, Celgene, Novartis and UCB

DOI: 10.1136/annrheumdis-2020-eular.1945

\section{$\mathrm{AB} 0810$ \\ IMPACT OF TOLERABILITY ON RETENTION OF CDMARDS IN PSORIATIC ARTHRITIS - IS IT A} CONCERN?

I. Jawad', M. K. Nisar ${ }^{1} .{ }^{1}$ Luton and Dunstable University Hospital, Luton, United Kingdom

Background: Most guidelines recommend the first line use of DMARDs in Psoriatic Arthritis (PsA). However, studies show that many conventional treatments like methotrexate are poorly tolerated. There is hitherto no published real-world data addressing the tolerability of DMARDs in PsA.

Objectives: Our objective was therefore to assess the drug management in PsA with focus on tolerability and the reasons for therapy cessation.

Methods: We conducted a retrospective analysis of all PsA patients enrolled in electronic database up to April 2019 at our university teaching hospital. We had access to full patient records including details on co-morbidities, drugs and disease management

Results: 335 patients were identified with a formal diagnosis of PsA. Mean age of the cohort was 46 years (13-81) and $58 \%$ were female. $48 \%$ of the group had clinically active disease. Same percentage were taking a single DMARD. $10 \%$ had trialled 3 or more drugs. $62 \%$ of patients had discontinued one or more DMARDs prior. The mean duration before discontinuing a DMARD was 9.9 months. Methotrexate was the best tolerated and on average discontinued after 13.4 months (range: 4 days to 10.9 years). Sulfasalazine and Hydroxychloroquine were discontinued after an average of 8.4 (11 days to 4.27 years) and 12.5 months (1.3 months to 2.88 years) respectively. Leflunomide was the least tolerated DMARD and stopped after an average of 5.5 months ( 7 days to 2.53 years). The main reason for stopping a medication was gastro-intestinal symptoms which accounted for $42 \%$ of all the reported side effects. This applied to both methotrexate $(43 \%)$ and sulfasalazine $(46 \%)$ discontinuation. The leading reasons for discontinuing Hydroxychloroquine were jointly Gl symptoms and other side effects at $43 \%$ each. Leflunomide was stopped in $50 \%$ of cases due to neurological symptoms.

Conclusion: To our knowledge, this is the first report confirming poor retention rate of oral DMARDs in a real world PsA cohort managed over 20 years. 